Mini Review

\title{
Electroanalytical Methods for Detecting Pesticides in Agricultural Products: a Review and Recent Developments
}

\author{
Guobin Chen ${ }^{1}$ and Peien Wang ${ }^{2 *}$ \\ ${ }^{1}$ Chongqing Key Laboratory of Spatial Data Mining and Big Data Integration for Ecology and \\ Environment, Rongzhi College of Chongqing Technology and Business University, Chongqing \\ 401320, PR China \\ ${ }^{2}$ College of History and Sociology, Xinjiang Normal University, Urumuqi, 830017, PR China \\ *E-mail: w18097795112@163.com
}

doi: $10.20964 / 2020.03 .35$

Received: 8 November 2019 / Accepted: 28 December 2019 / Published: 10 February 2020

\begin{abstract}
In modern agricultural production, the extensive use of pesticides plays an irreplaceable and important role in agricultural production because it effectively improves crop yield. As the most widely used and most toxic pesticides, organophosphorus pesticides can irreversibly inhibit the activity of cholinesterase, causing acetylcholine to accumulate in synapses in large quantities, thus interfering with the normal conduction of nerve impulses and even leading to the death of animals. At present, the main pesticide detection methods are traditional large-scale instrument detection methods. Although these methods have the advantages of high sensitivity and high accuracy, it is difficult to realize real-time and rapid field detection due to the expensive instruments and equipment, long time consumption and professional operation requirements. In recent years, electrochemical biosensors have been widely used in pesticide detection because of their simple operation, low cost and fast in situ detection. This review summarizes the research progress in the direct quantitative determination of organophosphorus pesticides using basic electrochemical sensors. The main performances of different types of carriers in terms of enzyme immobilization, as well as their advantages and disadvantages, are reviewed in detail.
\end{abstract}

Keywords: Pesticide determination; Electrochemical sensor; Organophosphorus hydrolase; Analytical method;

\section{$\underline{\text { FULL TEXT }}$}

(C) 2020 The Authors. Published by ESG (www.electrochemsci.org). This article is an open access article distributed under the terms and conditions of the Creative Commons Attribution license (http://creativecommons.org/licenses/by/4.0/). 